Published in final edited form as:

Antiviral Res. 2011 September ; 91(3): 259-266. doi:10.1016/j.antiviral.2011.06.009.

\title{
CK2 Inhibitors Increase the Sensitivity of HSV-1 to Interferon- $\beta$
}

\author{
Miles C. Smith ${ }^{1}$, Adam M. Bayless ${ }^{1}$, Erica T. Goddard ${ }^{1}$, and David J. Davido ${ }^{1,}$ \\ ${ }^{1}$ Department of Molecular Biosciences, University of Kansas, Lawrence, KS 660451
}

\begin{abstract}
Herpes simplex virus type 1 (HSV-1) requires the activities of cellular kinases for efficient replication. The host kinase, CK2, has been shown or is predicted to modify several HSV-1 proteins and has been proposed to affect one or more steps in the viral lifecycle. Furthermore, potential cellular and viral substrates of CK2 are involved in antiviral pathways and viral counterdefenses, respectively, suggesting that CK2 regulates these processes. Consequently, we tested whether pharmacological inhibitors of CK2 impaired HSV-1 replication, either alone or in combination with the cellular antiviral factor, interferon- $\beta$ (IFN- $\beta$ ). Our results indicate that the use of CK2 inhibitors results in a minor reduction in HSV-1 replication but enhanced the inhibitory effect of IFN- $\beta$ on replication. This effect was dependent on the HSV-1 E3 ubiquitin ligase, infected cell protein 0 (ICP0), which impairs several host antiviral responses, including that produced by IFN- $\beta$. Inhibitors of CK 2 did not, however, impede the ability of ICP0 to induce the degradation of two cellular targets: the promyelocyticleukemia protein (PML) and the DNAdependent protein kinase catalytic subunit (DNA-PKcs). Notably, this effect was only apparent for HSV-1, as the CK2 inhibitors did not enhance the antiviral effect of IFN- $\beta$ on either vesicular stomatitis virus or adenovirus type 5. Thus, our data suggest that the activity of CK2 is required for an early function during viral infection that assists the growth of HSV-1 in IFN- $\beta$-treated cells.
\end{abstract}

\section{Keywords}

HSV-1; CK2; IFN; ICP0; Ad5; VSV

\section{Introduction}

HSV-1 is a widespread human pathogen, infection by which can cause facial ulcerations, commonly known as cold sores, and in more extreme cases herpes stromal keratitis and encephalitis (Fields et al., 2007). HSV-1 has a biphasic lifecycle consisting of a lytic state that occurs primarily in the oral-facial epithelium and a latent state, where the viral genome establishes a quiescent infection in the neurons of the trigeminal ganglion (Fields et al., 2007). During the lytic cycle, the viral proteins are produced in a temporal cascade consisting of immediate-early (IE), early (E), and late (L) phases, with the expression of each phase dependent upon the preceding class (Honess and Roizman, 1974). The successful establishment of infection and progression through the lytic phase of replication requires the coordinated effort of many viral and cellular factors to stimulate viral gene expression to

(C) 2011 Elsevier B.V. All rights reserved.

"Corresponding Author. Mailing Address: University of Kansas, 1200 Sunnyside Avenue, 7047 Haworth Hall, Lawrence, KS 66045. Phone: (785) 864-4022. Fax: (785) 864-5294. ddavido@ku.edu.

Publisher's Disclaimer: This is a PDF file of an unedited manuscript that has been accepted for publication. As a service to our customers we are providing this early version of the manuscript. The manuscript will undergo copyediting, typesetting, and review of the resulting proof before it is published in its final citable form. Please note that during the production process errors may be discovered which could affect the content, and all legal disclaimers that apply to the journal pertain. 
ultimately produce infectious progeny virus (Honess and Roizman, 1974). A common theme in the regulation of these proteins is their post-translational modification by phosphorylation. AlthoughHSV-1 encodes at least two of its own protein-directed kinases UL13 and US3 -, efficient replication appears to require several cellular kinases, most notably certain cyclin-dependent kinases (Schang et al., 1998) and stress activated protein kinases (Karaca et al., 2004). HSV-1's requirement for cellular kinases makes the use of pharmacological inhibitors against these kinases a potential avenue for anti-herpetic treatments.

CK2, formerly called casein kinase II, is a ubiquitously expressed and highly conserved cellular serine/threonine kinase that targets a S/T-X-X-D/E motif. With over300 known cellular substrates, CK2 is implicated as functioning in a wide variety of cellular processes, including apoptosis, proliferation, and transcription, where its activity can be broadly described as pro-cell survival and pro-cell growth (reviewed in (Meggio and Pinna, 2003)). While there are many cellular factors implicated in the regulation of its activity, CK2 is typically described as constitutively expressed and active (Allende and Allende, 1995; Montenarh, 2010); however, this regulation is important as CK2 is frequently found to be overactive in a number of pathogenic conditions, including tumorigenesis (Ahmad et al., 2005).

In addition to its cellular targets, proteins from several different viruses have been reported to serve as CK2 substrates. In the case of HSV-1, proteins from all three kinetic classes, including the IE proteins ICP0 (Davido et al., 2005), ICP4 (Bates and DeLuca, 1998), ICP27 (Zhi and Sandri-Goldin, 1999); the E protein ICP6 (Conner, 1999); and the L proteins VP1/2 (Morrison et al., 1998), VP13/14 (Morrison et al., 1998), VP16 (O'Reilly et al., 1997), VP22 (Elliott et al., 1999), and gE (Wisner et al., 2000) contain CK2 consensus phosphorylation sites, and in several instances mutation of these sites compromises viral replication (Xia et al., 1996; Davido et al., 2005; Potel and Elliott, 2005; Rojas et al., 2010). Perhaps owing to the potential importance of CK2 inHSV-1 replication, CK2 is the only cellular kinase, to date, that has been shown to be packaged in the tegument of the assembled virion (Loret et al., 2008). Additionally, HSV-1 has been reported to stimulate CK2 activity through the IE protein ICP27, which physically interacts and relocalizes CK2 at early times during infection (Koffa et al., 2003).Of these viral targets, both ICP0 and ICP27 are involved in counteracting the repressive effects of the cellular antiviral pathway known as the interferon (IFN) response. The IFN response is triggered by viral infection and results in the upregulation of a number of cellular factors that collectively serve to impede viral replication (Haller et al., 2006). ICP0 is an E3 ubiquitin ligase that promotes viral gene expression and contributes to a successful initiation of infection by inducing the degradation of a number of cellular targets, including several that are upregulated by IFNs (Chelbi-Alix and de Thé, 1999; Parkinson et al., 1999; Lomonte et al., 2001; Everett et al., 2006; Lilley et al., 2010). ICP27 is a multifunctional mRNA/protein nuclear import/export shuttling factor and regulatory protein that promotes viral mRNA translation and inhibits cellular protein (Sandri-Goldin, 2008). While this implicates CK2 playing a role in the lifecycle of HSV-1, the impact of inhibiting or removal of CK2 activity on HSV-1 replication has remained largely unexplored.

Previous studies examining the role of CK2 during HSV-1 infection were unable to assess the effect of CK2 on replication due to limitations of the inhibitors available at the time. For example, at the concentrations necessary to inhibit CK2, a commonly used CK2 inhibitor, 5,6-dichloro-1- $\beta$-D-ribofuranosylbenzimidazole (DRB), also blocks the activity of CDK9 (Koffa et al., 2003; Wang and Fischer, 2008). In this study, we have taken advantage of recently developed compounds that are more selective in their inhibitory properties. Our results indicate that CK2 inhibitors have a minor impact on HSV-1 replication in cultured 
human fibroblasts; however, the use of CK2 inhibitors compromises the ability of the virus to replicate in cells pretreated with the type I interferon, IFN- $\beta$, in a manner that was only observed with HSV-1.

\section{Materials and Methods}

\subsection{Cell and viruses}

Human embryonic lung (HEL) cells were obtained from the American Type Culture Collection (CCL-137) and grown in Minimum Essential Medium Eagle's Alpha Modification ( $\alpha$ MEM) supplemented with 10\% fetal bovine serum (FBS), 2 mM Lglutamine, $10 \mathrm{U} / \mathrm{mL}$ penicillin, and $10 \mathrm{U} / \mathrm{mL}$ streptomycin. Vero cells and $\mathrm{L} 7$ cells, which are Vero cells that contain the ICPO gene (Samaniego et al., 1997), were grown in Dulbecco's modified Eagle's medium supplemented with 5\% FBS, 2 mM L-glutamine, 10 $\mathrm{U} / \mathrm{mL}$ penicillin, and $10 \mathrm{U} / \mathrm{mL}$ streptomycin. KOS (Smith, 1964) is the wild type HSV-1 strain used in these studies. 7134 is an ICP0-null mutant in which the ICPOopen reading frame is replaced by the E. colilacZ gene (Cai and Schaffer, 1989). KOS and 7134 viral stocks were prepared in Vero cells and titered on either Vero (for KOS) or L7 cells (for 7134) as previously described (Schaffer et al., 1973; Davido et al., 2005). Adenovirus 5 (Ad5) was purchased from the American Type Culture Collection (VR-5) and propagated and titered on HEK-293 cells (Halford et al., 2001). The vesicular stomatitis virus recombinant, VSV-eGFP (Das et al., 2006), which encodes the enhanced green fluorescent protein gene inserted between the G and L genes, was a gift from Dr. AsitPattnaik and was propagated and titered on Vero cells.

\subsection{Reagents}

The CK2 inhibitors4,5,6,7-tetrabromo-1H-benzotriazole (TBB) and 2-

dimethylamino-4,5,6,7-tetrabromo- $1 H$-benzimidazole (DMAT) were purchased from EMD Chemicals and 2-(4,5,6,7-tetrabromo-2-(dimethylamino)-1H-benzo[d]imidazol-1-yl)acetic acid (TMCB) from Ascent Scientific. All CK2 inhibitors were constituted in DMSO (Fischer Scientific). TBB and TMCB were used at $50 \mu \mathrm{M}$ and DMAT at $20 \mu \mathrm{M}$. Recombinant human IFN- $\beta$ was purchased from R\&D Systems.

\subsection{Viral plaque reduction assays}

For HSV-1 plaque reduction assays, HEL cells were plated in 24-well plates. Upon reaching $70 \%$ confluency, cells were either mock treated or treated with a given concentration of IFN- $\beta$. After 16 hours of IFN-treatment, cells were prewashed with either medium; medium plus IFN- $\beta$; medium plus DMSO (as vehicle control), TBB, or TMCB; or medium plus IFN$\beta$ and either vehicle or CK2 inhibitor. Cells were then infected with 10 -fold serial dilutions of HSV-1 in the aforementioned media. At 1 hour post infection (hpi), the cells were overlaid with cell culture medium containing $0.5 \%$ methylcellulose and the appropriate compounds. At 3 days post infection (dpi), monolayers were fixed with $3.7 \%$ formaldehyde, probed with a horseradish peroxidase (HRP)-conjugated anti-HSV antibody (Dako), and the resulting plaques were visualized with Vector Red substrate (Vector Labs). Plaque areas were determined by capturing images of immunohistochemically stained plates with a flatbed scanner (Canon), measuring the number of pixels that corresponded to an individual plaque in Adobe Photoshop. Pixel values were converted to $\mathrm{mm}^{2}$ by dividing by the number of pixels per inch for the image. Four to twenty plaques were measured per treatment from two experiments.

For Ad5 plaque reduction assays, HEL cells were treated and infected as described for the HSV- 1 plaque assays. At 5 dpi, cells were washed once with PBS, fixed for 5 minutes with $5 \%$ formaldehyde in PBS, washed three times with PBS, permeabilized at $4^{\circ} \mathrm{C}$ for 15 
minutes with $0.5 \%$ NP-40 in PBS, and washed an additional three times with PBS. Ad5 infected cells were detected by probing the cells with a FITC-conjugated anti-adenovirus antibody (B65140F, Meridian Life Science)diluted in PBS and the resulting plaques and cells were visualized and counted by fluorescence microscopy (Nikon).

For VSV-eGFP reduction assays, HEL cells were again treated and infected as described for HSV-1 plaque assays with the exceptions that the cells were treated with $10 \mathrm{U} / \mathrm{mL}$ of IFN- $\beta$, and the monolayers were overlaid with $2 \%$ methylcellulose. At $1 \mathrm{dpi}$, the cells were washed three times with PBS and fixed with 3.7\% formaldehyde in PBS for 5 minutes at room temperature. Plaques were detected and counted by fluorescence microscopy (Nikon).

\subsection{Viral yield assays}

HEL cells were plated at $1 \times 10^{5}$ cells per well in 12-well plates and one day later were either mock treated or treated with IFN- $\beta$. 16 hours later, cells were pre washed as described above and subsequently infected for $1 \mathrm{~h}$ in the presence of the appropriate compounds with either KOS or 7134 at a multiplicity of infection of 1 . After $1 \mathrm{~h}$ the cells were overlaid with cell medium containing the previously described compounds. At 24 hpi, cells were harvested, and viral titers were determined on Vero or L7 cells for KOS or 7134, respectively.

\subsection{Western blots}

HEL cells were plated, treated, and infected as described for HSV-1 yield assays. 12 and 24hpi, cells were washed once with PBS and then scraped into boiling Laemmliloading buffer (Laemmli, 1970)containing $1 \mu \mathrm{g} / \mathrm{mL}$ leupeptin, $1 \mu \mathrm{g} / \mathrm{mL}$ aprotinin, 1 mMphenylmethanesulfonylfluoride, $10 \mathrm{mM}$ sodium vanadate, $50 \mathrm{mM}$ sodium fluoride, and $20 \mathrm{mM}$ N-ethylmalemide. $10 \%$ of each sample was resolved on a 4-12\% Bis-tris polyacrylamide gel, transferred to nitrocellulose, blocked at room temperature for $1 \mathrm{~h}$ with $2 \%$ nonfat dry milk in Tris-buffered saline with $0.1 \%$ Tween 20 (TBS-T), and probed overnight at $4^{\circ} \mathrm{C}$ with antibodies directed against either ICP4 (H1A021, EastCoast), UL42 (mAB3678, Millipore), PML (A301-167A, Bethyl Laboratories), or $\beta$-actin ((I-19)-R, Santa Cruz Biotechnology). Membranes were then washed three times with TBS-T and probed at room temperature with either goat-anti-mouse $\operatorname{IgG}$ or goat-anti-rabbit IgG conjugated to HRP (Jackson Immunoresearch). Membranes were again washed with TBS-T and developed with chemiluminescent substrate (Femto ECL, Pierce Laboratories). Some membranes were stripped by incubation in $2 \%$ SDS, $100 \mathrm{mM} \beta$-mercaptoethanol, $62.5 \mathrm{mMTris}-\mathrm{HCl}$ (pH 6.7) at $55^{\circ} \mathrm{C}$ for 30 minutes. These membranes were thoroughly washed with TBS-T, blocked at room temperature for $1 \mathrm{~h}$ with $2 \%$ milk/TBS-T, and probed overnight at $4{ }^{\circ} \mathrm{C}$ with antibodies directed against either ICP0 (sc-53070, Santa Cruz Biotechnology) or VP5 (ab6508, Abcam). The membranes were then washed, probed with a secondary HRP-conjugated antibody, and developed as before. Chemiluminescence was detected using an Image Station 4000R (Kodak) and Care stream Molecular Imaging software. Images were assembled using Photoshop and Illustrator (Adobe Systems) and band intensities were measured by densitometry analyses using ImageJ.

\subsection{Immunofluorescence}

HEL cells were plated at $1 \times 10^{5}$ cells per well in collagen-coated glass bottom 24-well plates, treated, and infected as described above for the HSV-1 yield assays. At $12 \mathrm{hpi}$, the cells were fixed and permeabilized as described above in the Ad5 plaque reduction assays. Samples were blocked with $1 \%$ BSA, 5\% FCS, and 1\% goat serum in PBS for $1 \mathrm{~h}$ at room temperature. Cells were then probed with antibodies against ICP0 (sc-53070), PML (A301-167A), and DNA-PKcs (sc-5282, Santa Cruz Biotechnology) for $1 \mathrm{~h}$ in blocking solution at $37^{\circ} \mathrm{C}$. Monolayers were washed with PBS and probed with goat-anti-mouse 
immunoglobin (IgG) 2b Dylight 488 (Jackson Immunology), goat-anti-rabbit IgGAlexa 405 (Molecular Probes), and goat-anti-mouse IgG1a Dylight 594 (Jackson Immunoresearch) to detect ICP0, PML, and DNA-PKcs, respectively. Proteins were viewed by confocal fluorescent microscopy (Olympus) and captured with a digital camera (Hamamatsu). Images were assembled using Photoshop and Illustrator (Adobe Systems).

\section{Results}

\subsection{CK2 inhibitors reduce the plating efficiency and plaquing of HSV-1 in IFN- $\beta$-treated cells}

We initially sought to determine the requirement for CK2 activity during HSV-1 replication. To this end, we employed plaque reduction assays to test the effect that two specific CK2 inhibitors, TBB $\left(\mathrm{IC}_{50}=0.15 \mu \mathrm{M}\right)$ and TMCB (IC50 $\left.=0.50 \mu \mathrm{M}\right)$ (Pagano et al., 2008), both of which block the active site of CK2, have on the plating efficiency and spread of HSV-1 in HEL cells. Additionally, because cellular factors responsible for the innate antiviral response (e.g., IFN) and the viral factors that counteract this response are either known to be or are potential CK2 substrates, we also examined how these inhibitors affected the ability of HSV-1 to plaque in the presence of a type 1 interferon, IFN- $\beta$. HEL cells were untreated or pretreated with $1000 \mathrm{U} / \mathrm{mL}$ of IFN- $\beta$ for 16 hours and then infected with serial diluted HSV-1 in the presence of the compounds as listed in Table 1. In these and subsequent assays, TBB was used at $50 \mu \mathrm{M}$ as previously described (Scaglioni et al., 2006), while a preliminary dose response curve suggested that the same concentration was appropriate for TMCB (data not shown); DMSO was used at $0.5 \% \mathrm{v} / \mathrm{v}$ as a vehicle control. As seen in Table 1 , the use of each CK2 inhibitor alone resulted in only a modest reduction in plaque size (3.9- and 1.4-fold decrease for TBB and TMCB, respectively) and plating efficiency of HSV-1 ( 0 and 2-fold decrease for TBB and TMCB, respectively) compared to the untreated samples. As expected, IFN- $\beta$ reduced plaque size and plating efficiency 26 - and 25 -fold, respectively. When DMSO was added to IFN- $\beta$, it had a slight effect on plaque size (1.8fold decrease versus IFN- $\beta$ alone), and a negligible impact on plating efficiency. However, the combination of IFN- $\beta$ and either CK2 inhibitor further reduced viral plaque size and plating efficiency (3.5- and 2.8-fold for TBB, and 2.6- and 2.1-fold for TMCB, respectively), compared to IFN- $\beta$-treated cells. These results were further confirmed when we used a third CK2 inhibitor, DMAT (data not shown). We then tested whether these inhibitors would also enhance the IFN-sensitivity in cells treated with a suboptimal concentration $(50 \mathrm{U} / \mathrm{mL})$ of IFN- $\beta$. This reduced amount of IFN, in either media alone or with DMSO, indeed proved to be less effective at reducing either plaque size $(\sim 5$-fold $)$ or plating efficiency (4-fold). Again, we found that both inhibitors, in combination with IFN- $\beta$, reduced the plating efficiency of HSV-1 (9- and 7-fold) and both decreased viralplaque size (42.1- and 10.3-fold for TBB and TMCB, respectively) beyond that of IFN alone. These decreases in viral replication were not due to a loss of cell viability, as treatment with IFN, CK2 inhibitor, or a combination of IFN and inhibitor did not increase in cell death as measured by trypan blue exclusion assay. Specifically, by three days post treatment, there was a $15 \%$ loss in cell viability with mock-treated HEL, where all other treatment groups had a similar (9-23\%)loss in cell viability.

\subsection{CK2 inhibitors reduce viral replication in IFN- $\beta$-treated cells in an ICP0-dependent manner}

We then examined whether the decreases in the plating efficiencies and plaque sizes observed in Table 1 correlated with reductions in productive infection. In addition, we included an ICP0-null mutant virus in these experiments because ICP0 has been shown to assist HSV-1 in counteracting the IFN response (Mossman et al., 2000; Eidson et al., 2002; Härle et al., 2002)and is a potential target of CK2 phosphorylation (Davido et al., 2005). 
Cells were pretreated with IFN- $\beta$ and infected with 1 plaque forming unit (PFU) per cell of either HSV-1 or an ICP0-null mutant virus in the presence of the reagents. As shown in Figure 1, IFN- $\beta$ treatment alone reduced the replication of HSV- 1 by 28 -fold and the ICP0null mutant by 212 -fold, while treatment with DMSO or either CK2 inhibitor resulted in a minor ( $\sim 2$ fold) reduction in replication. However, when the inhibitors were used in conjunction with IFN- $\beta$, the replication of HSV-1 was decreased by a factor of 145 -fold with TBB and 69-fold with TMCB where as the ICP0-null mutant was reduced by a factor of 182-fold with TBB and 141-fold with TMCB. These results demonstrate that CK2 inhibitors increase the antiviral effects of IFN- $\beta$ on HSV-1 productive infection and suggest the enhancement by the CK2 inhibitors may be related to the anti-IFN-mediated activity of ICP0.

\subsection{CK2 inhibitors in conjunction with IFN- $\beta$ decrease the levels of early and late proteins}

To identify the point(s) in the viral lifecycle impaired by the combination of CK2 inhibitor and IFN- $\beta$, we analyzed the accumulation of specific viral proteins by western blot analysis. HEL cells were again pretreated with IFN- $\beta$ and infected with HSV-1at 1 PFU per cell in the presence of the reagents. At 12 and 24 hpi, Western blots were used to assess the levels of the viral proteins ICP4, UL42, and VP5 as representative examples of IE, E, and Lproteins, respectively. The results in Figure 2 show that, as expected, the CK2 inhibitors alone had little effect on the accumulation of the viral proteins examined. IFN treatment delayed viral protein expression, with an overall reduction for all 3 kinetic classes tested. While the combination of IFN- $\beta$ and CK2 inhibitor did not decrease ICP4 levels more than for IFN- $\beta$ alone, there was a decline in UL42 (>100-fold for TBB and TMCB) and VP5 (>9-fold for TBB and TMCB) levels at 24 hpi. These results indicate that the use of the CK2 inhibitors impairs the function of at least one IE protein to activate the synthesis of $\mathrm{E}$ and $\mathrm{L}$ proteins.

\subsection{CK2 inhibitors do not affect the stability of ICP0-directed targets of degradation}

Since the viral replication assays indicated that the CK2 inhibitors did not increase the IFN sensitivity of an ICP0-null mutant, we assayed the impact that the CK2 inhibitors had on the E3 ubiquitin ligase activity of ICP0. ICP0, thought itsE3 ubiquitin ligase activity, appears to induce the proteosomal-dependent degradation of a number of cellular targets in order to assist HSV-1 in overcoming cellular antiviral responses. As a result, we examined whether the CK2 inhibitors impaired ICP0's ability to induce the loss of two cellular targets, PML and DNA-PKcs. HEL cells were pretreated with IFN- $\beta$ and infected with HSV-1 in the presence of CK2 inhibitors as described above. At $12 \mathrm{hpi}$, the cells were assayed for the presence of ICP0, PML, and DNA-PKcs by immunofluorescence; at 12 and $24 \mathrm{hpi}$, cell lysates were analyzed for PML and ICP0 levels by western blot. As shown in Figure 3, while the use of either CK2 inhibitor, IFN- $\beta$, or the combination of CK2 inhibitor and IFN- $\beta$ decreased the number of ICP0-positive cells, a majority of cells that were positive for ICP0 either showed a decrease or loss of DNA-PKcs and PML, irrespective of treatment. When we examined PML levels by western blot (Figure 4), however, it appeared that treatment with TBB alone, in the absence of HSV-1, resulted in a slight stabilization of PML at $12 \mathrm{hpi}$, and at 24 hpi when TBB was used with IFN- $\beta$ in HSV-1 infected cells. While this might indicate that CK2 is involved in PML degradation, it is also likely that PML levels were higher due to a smaller proportion of cells expressing ICP0 (Figure 3 ). These results suggest that the CK2 inhibitors do not compromise the E3 ubiquitin ligase activity of ICP0, or at least the ability of ICP0 to induce the degradation of two of its targets.

\subsection{The enhanced effect of CK2 inhibitors on IFN is observed with HSV-1 but not VSV and Ad5}

Given our results, there are two possibilities to explain how the use of CK2 inhibitors increase the sensitivity of HSV-1 to an IFN- $\beta$-induced antiviral response: CK2 negatively 
regulates one or more cellular components of the IFN response that repress HSV-1 replication and thus the inhibitors increase the overall potency of IFN- $\beta$, or CK2 alters the activities of one or more viral components that impairs the ability of IFN to restrict HSV-1 replication. To test these possibilities, we examined the effect that the CK2 inhibitors had on the plating efficiency of two other viruses, VSV and Ad5. VSV and Ad5 were chosen for these studies as they represent viruses that are genetically distinct from HSV-1 and are either very sensitive to the effects of IFN (for VSV) or show high levels of IFN resistance (for Ad5) (Anderson and Fennie, 1987). HEL cells were pretreated with IFN- $\beta$ for $16 \mathrm{~h}$ and infected with 10-fold serial dilutions of either Ad5 or the VSV recombinant, VSV-eGFP, as described for HSV-1. At 1 dpi, VSV-eGFP-infected monolayers were fixed and GFPpositive plaques counted; Ad5-infected monolayers were fixed at $5 \mathrm{dpi}$, stained with an antibody directed against adenovirus, and plaques visualized by immunofluorescence. As shown in Table 2, VSV replication was highly impaired by pretreatment with IFN, whereas Ad5 was highly resistant, as expected. Similar to HSV-1, both of the CK2-inhibitors had little to no effect on either VSV or Ad5 replication; however, unlike HSV-1, neither inhibitor increased the IFN-sensitivity of VSV or Ad5. These data suggest that the activity of CK2 is necessary for the ability of HSV-1 to diminish the effects of IFN on replication, that this mechanism is specific to HSV-1, and that, at least in HEL cells, CK2 activity is not required for the plaquing of either VSV or Ad5 regardless of the IFN response.

\section{Discussion}

HSV-1 requires the activity of a number of both viral and cellular kinases for efficient viral replication. Because several of the potential viral CK2 substrates are involved in overcoming cellular intrinsic and innate antiviral defenses and a number of those defenses are themselves CK2 phosphorylation substrates (Zhi and Sandri-Goldin, 1999; Briggs et al., 2001; Davido et al., 2005; Scaglioni et al., 2006; Sun et al., 2011), we investigated the effect that CK2 inhibitors have on HSV-1 replication in cells treated with the type I interferon, IFN- $\beta$. Surprisingly, while the inhibitors alone had little impact on replication, they functioned synergistically with IFN- $\beta$. When we investigated the point in the viral lifecycle affected, we found that the levels of the IE proteins ICP0 and ICP4 were relatively unaltered, while there was large decrease in both the E protein, UL42, and L protein, VP5. This result suggests that the CK2 inhibitors impair the activity of an IE protein that functions to overcome the IFN response. Of the HSV-1 IE proteins, both ICP0 and ICP27 have been identified as antagonists of the IFN response. This study focused on whether inhibition of CK2 activity influenced ICP0's ability to counteract the IFN response. We were unable to examine the role of ICP27 in this study as the loss of ICP27 is deleterious (Sacks et al., 1985) and, as is discussed below, mutations of the CK2 phosphoacceptor sites of ICP27 significantly impair HSV-1 replication (Rojas et al., 2010). Our results demonstrate that the CK2 inhibitors were unable to increase the IFN sensitivity of an ICP0-null mutant, indicating a requirement for CK2 inICP0's anti-IFN activity. To determine if the combination of CK2 inhibitor and IFN$\beta$ impede a key function of ICP0, we examined the ability of ICP0 to direct the degradation of two of its targets, PML and DNA-PKcs, in cells treated with the CK2 inhibitors. In these assays, we did not observe the inhibitors inducing a stabilization of either target. While ICP0 may be a CK2 substrate, it appears that phosphorylation of ICP0 by CK2 is not necessary for its E3 ubiquitin ligase activity in our assays. It is possible that phosphorylation of ICP0 by CK2 may affect an activity of ICP0 not linked to its E3 ligase activity in order to promote efficient viral replication in the presence of IFN- $\beta$, or that ICP0 activates the expression of an $\mathrm{E}$ and/or $\mathrm{L}$ gene and that the protein product of this viral gene is phosphorylated byCK2 to inactivate components in the IFN response. Regarding the former possibility, we have previously shown in transient transfection assays that ICP0 mutated in two regions containing potential CK2 phosphorylation sites exhibit defects in its transactivation activity 
(Davido et al., 2005); however, we have not tested the effects of these mutations during viral infection in our assays.

We also noted in this study that the CK2 inhibitors alone do not appear to greatly impede the replication of HSV-1, thus making CK2 activity likely dispensable for the growth of HSV-1. This is unexpected given the number of HSV-1 proteins that have been identified as potential CK2 substrates and that mutation of these CK2 phosphorylation sites is detrimental to viral replication (Xia et al., 1996; Wisner et al., 2000; Potel and Elliott, 2005; Boutell et al., 2008; Rojas et al., 2010). As one example, mutation of CK2 phosphorylation sites in the IE protein, ICP27, impairs viral replication (Rojas et al., 2010). This mutation, however, may prevent a large conformational shift in the N-terminus of ICP27 that appears to be necessary for its functions (Corbin-Lickfett et al., 2010) and do so in a CK2 phosphorylation-independent manner. It is also probable that residual CK2 kinase activity may remain after TBB or TMCB treatment or that the stimulation of CK2 activity by ICP27 (Koffa et al., 2003) is able to overcome the effect of the CK2 inhibitors; however, these possibilities seem unlikely as a further reduction in plaque size or plating efficiency was not observed when higher levels of either inhibitor were used (data not shown).

While the enhanced sensitivity of IFN induced by CK2 inhibitors requires at least one HSV-1 protein, it is also plausible that this effect could be mediated by one more cellular factors. To explore this possibility, we examined whether the CK2 inhibitors influenced the IFN-sensitivity of two other viruses, VSV and Ad5. We found that the CK2 inhibitors used alone affected neither virus. While IFN- $\beta$ impaired the replication of VSV, neither inhibitor increased this impairment beyond that of IFN- $\beta$ alone. Ad5, on the other hand, was largely impervious to the effect of IFN- $\beta$ and the use of the CK2 inhibitors failed to change this. Although the CK2 inhibitors alone did not alter VSV replication, it was recently reported that use of the CK2 inhibitor, DMAT, or siRNA-mediated silencing of CK2 increased VSV replication (Sun et al., 2011). Likewise, the CR2 region of the Ad5 E1A protein contains a consensus CK2 phosphorylation motif (Whalen et al., 1996). In the case of VSV, the discrepancy may lie in the cell lines used, as those studies were carried out in the highly transformed HEK-293s. As for Ad5, while the CK2 site was implicated in binding to the retinoblastoma protein and resistance to Ad-induced cell death, the role of phosphorylation at this site in Ad5 replication is likely to be minimal as mutation of this site failed to affect E1A transactivation activity (Whalen et al., 1996). In either case, the fact that the CK2 inhibitors did not increase the IFN- $\beta$ sensitivity of VSV or Ad5 suggests that the CK2 inhibitors compromise an anti-IFN mechanism that is specific to HSV-1.

While we did not note either CK2 inhibitor having a large impact on the replication of either VSV or Ad5, a number of other viruses have shown a dependence on CK2 activity for efficient replication. For example, CK2 phosphorylation is involved in multiple steps of the human immunodeficiency virus1 (HIV-1) lifecycle, including reverse transcription and gene expression (Critchfield et al., 1997; Harada et al., 1999), and treatment with a CK2 inhibitor has been reported to inhibit HIV-1 replication (Critchfield et al., 1997). Additionally, a CK2 inhibitor was recently shown to have antiviral activity towards varicella-zoster virus (Rowe et al., 2010). It remains to be seen, however, if the enhancement by CK2 inhibitors on the potency of IFN is restricted to HSV-1 or if this extends to other members of the herpesvirus family or more broadly to other viral families. Nevertheless, CK2 inhibitors show promise as anti-HSV-1 therapeutic agents when used in combination with other antiviral treatments. Notably, the CK2 inhibitor, TBB, has been shown to be efficacious in limiting retinal pathologies in mice (Ljubimov et al., 2004). 


\section{Acknowledgments}

This work was supported in part by the NIH grant number P20 RR016475 from the INBRE Program of the National Center for Research Resources and Public Health Service grant RO1AI72357 from the National Institute of Allergy and Infectious Diseases. The content is solely the responsibility of the authors and does not necessarily represent the official views of the National Institutes of Health.

We thank Jae Hoon Lee and Steve Haenchen for assistance with statistical analysis.

\section{Glossary}

\begin{tabular}{|c|c|}
\hline Ad5 & adenovirus type 5 \\
\hline аMEM & Minimum Essential Medium Eagle Alpha Modification \\
\hline ANOVA & Analysis of variance \\
\hline CDK9 & cyclin-dependent kinase 9 \\
\hline DMAT & 2-dimethylamino-4,5,6,7-tetrabromo-1 $H$-benzimidazole \\
\hline DMEM & Dulbecco's modified Eagle's medium \\
\hline DMSO & dimethylsulfoxide \\
\hline DNA-PKes & DNA-dependent protein kinase catalytic subunit \\
\hline dpi & days post infection \\
\hline DRB & 5,6-dichloro-1- $\beta$-D-ribofuranosylbenzimidazole \\
\hline $\mathbf{E}$ & early \\
\hline FBS & fetal bovine serum \\
\hline HEL & human embryonic lung \\
\hline HIV-1 & human immunodeficiency virus 1 \\
\hline hpi & hours post infection \\
\hline HRP & horseradish peroxidase \\
\hline HSV-1 & herpes simplex virus type 1 \\
\hline $\mathbf{g E}$ & glycoprotein E \\
\hline GFP & green fluorescent protein \\
\hline ICPO & infected cell protein 0 \\
\hline ICP4 & infected cell protein 4 \\
\hline ICP6 & infected cell protein 6 \\
\hline ICP27 & infected cell protein 27 \\
\hline IE & immediate early \\
\hline IFN- $\beta$ & interferon- $\beta$ \\
\hline $\mathbf{L}$ & late \\
\hline PFU & plaque forming unit \\
\hline PML & promyelocytic leukemia protein \\
\hline SEM & standard error of the mean \\
\hline SiRNA & small interfering RNA \\
\hline
\end{tabular}


TBB

TBS-T

TMCB

VP1/2

VP13/14

VP16

VP22

VSV
4,5,6,7-tetrabromo-1H-benzotriazole

tris buffered saline plus tween 20

2-(4,5,6,7-tetrabromo-2-(dimethylamino)-1H-benzo[d]imidazol-1-yl)acetic acid

viral protein $1 / 2$

viral protein $13 / 14$

viral protein 16

viral protein 22

vesicular stomatitis virus

\section{References}

Ahmad KA, Wang G, Slaton J, Unger G, Ahmed K. Targeting CK2 for cancer therapy. Anticancer Drugs. 2005; 16:1037-1043. [PubMed: 16222144]

Allende JE, Allende CC. Protein kinases. 4. Protein kinase CK2: an enzyme with multiple substrates and a puzzling regulation. FASEB J. 1995; 9:313-323. [PubMed: 7896000]

Anderson KP, Fennie EH. Adenovirus early region 1A modulation of interferon antiviral activity. J Virol. 1987; 61:787-795. [PubMed: 3027405]

Bates PA, DeLuca NA. The polyserine tract of herpes simplex virus ICP4 is required for normal viral gene expression and growth in murine trigeminal ganglia. J Virol. 1998; 72:7115-7124. [PubMed: 9696805]

Boutell C, Everett RD, Hilliard J, Schaffer PA, Orr A, Davido DJ. Herpes simplex virus type 1 ICP0 phosphorylation mutants impair the E3 ubiquitin ligase activity of ICP0 in a cell type-dependent manner. J Virol. 2008; 82:10647-56. [PubMed: 18715910]

Briggs LJ, Johnstone RW, Elliot RM, Xiao CY, Dawson M, Trapani JA, Jans DA. Novel properties of the protein kinase CK2-site-regulated nuclear- localization sequence of the interferon-induced nuclear factor IFI 16. Biochem J. 2001; 353:69-77. [PubMed: 11115400]

Cai WZ, Schaffer PA. Herpes simplex virus type 1 ICP0 plays a critical role in the de novo synthesis of infectious virus following transfection of viral DNA. J Virol. 1989; 63:4579-4589. [PubMed: 2552142]

Chelbi-Alix MK, de Thé H. Herpes virus induced proteasome-dependent degradation of the nuclear bodies-associated PML and Sp100 proteins. Oncogene. 1999; 18:935-941. [PubMed: 10023669]

Conner J. The unique $\mathrm{N}$ terminus of herpes simplex virus type 1 ribonucleotidereductase large subunit is phosphorylated by casein kinase 2, which may have a homologue in Escherichia coli. J Gen Virol. 1999; 80:1471-1476. [PubMed: 10374965]

Corbin-Lickfett KA, Rojas S, Li L, Cocco MJ, Sandri-Goldin RM. ICP27 phosphorylation site mutants display altered functional interactions with cellular export factors Aly/REF and TAP/NXF1 but are able to bind herpes simplex virus 1 RNA. J Virol. 2010; 84:2212-2222. [PubMed: 20015986]

Critchfield JW, Coligan JE, Folks TM, Butera ST. Casein kinase II is a selective target of HIV-1 transcriptional inhibitors. Proc Natl Acad Sci USA. 1997; 94:6110-6115. [PubMed: 9177178]

Das SC, Nayak D, Zhou Y, Pattnaik AK. Visualization of intracellular transport of vesicular stomatitis virus nucleocapsids in living cells. J Virol. 2006; 80:6368-6377. [PubMed: 16775325]

Davido DJ, von Zagorski WF, Lane WS, Schaffer PA. Phosphorylation site mutations affect herpes simplex virus type 1 ICP0 function. J Virol. 2005; 79:1232-1243. [PubMed: 15613350]

Eidson KM, Hobbs WE, Manning BJ, Carlson P, DeLuca NA. Expression of herpes simplex virus ICP0 inhibits the induction of interferon-stimulated genes by viral infection. J Virol. 2002; 76:2180-2191. [PubMed: 11836395]

Elliott G, O'Reilly D, O'Hare P. Identification of phosphorylation sites within the herpes simplex virus tegument protein VP22. J Virol. 1999; 73:6203-6206. [PubMed: 10364384] 
Everett RD, Rechter S, Papior P, Tavalai N, Stamminger T, Orr A. PML contributes to a cellular mechanism of repression of herpes simplex virus type 1 infection that is inactivated by ICP0. $\mathrm{J}$ Virol. 2006; 80:7995-8005. [PubMed: 16873256]

Fields, BN.; Knipe, DM.; Howley, PM.; Griffin, DE. Fields Virology. Lippincott Williams \& Wilkins; 2007.

Härle P, Sainz B, Carr DJJ, Halford WP. The immediate-early protein, ICP0, is essential for the resistance of herpes simplex virus to interferon- $\alpha / \beta$; Virology. 2002; 293:295-304. [PubMed: 11886249]

Halford WP, Kemp CD, Isler JA, Davido DJ, Schaffer PA. ICP0, ICP4, or VP16 expressed from adenovirus vectors induces reactivation of latent herpes simplex virus type 1 in primary cultures of latently infected trigeminal ganglion cells. J Virol. 2001; 75:6143-6153. [PubMed: 11390616]

Haller O, Kochs G, Weber F. The interferon response circuit: induction and suppression by pathogenic viruses. Virology. 2006; 344:119-130. [PubMed: 16364743]

Harada S, Haneda E, Maekawa T, Morikawa Y, Funayama S, Nagata N, Ohtsuki K, Nagata N, Ohtsuki K. Casein kinase II (CK-II)-mediated stimulation of HIV-1 reverse transcriptase activity and characterization of selective inhibitors in vitro. Biol Pharm Bull. 1999; 22:1122-1126. [PubMed: 10549869]

Honess RW, Roizman B. Regulation of herpesvirus macromolecular synthesis I. Cascade regulation of the synthesis of three groups of viral proteins. J Virol. 1974; 14:8-19. [PubMed: 4365321]

Karaca G, Hargett D, McLean TI, Aguilar JS, Ghazal P, Wagner EK, Bachenheimer SL. Inhibition of the stress-activated kinase, p38, does not affect the virus transcriptional program of herpes simplex virus type 1. Virology. 2004; 329:142-156. [PubMed: 15476882]

Koffa MD, Kean J, Zachos G, Rice SA, Clements JB. CK2 Protein kinase is stimulated and redistributed by functional herpes simplex virus ICP27 protein. J Virol. 2003; 77:4315-4325. [PubMed: 12634389]

Laemmli UK. Cleavage of structural proteins during the assembly of the head of bacteriophage T4. Nature. 1970; 227:680-685. [PubMed: 5432063]

Lilley CE, Chaurushiya MS, Boutell C, Landry S, Suh J, Panier S, Everett RD, Stewart GS, Durocher D, Weitzman MD. A viral E3 ligase targets RNF8 and RNF168 to control histone ubiquitination and DNA damage responses. EMBO J. 2010; 29:943-955. [PubMed: 20075863]

Ljubimov AV, Caballero S, Aoki AM, Pinna LA, Grant MB, Castellon R. Involvement of protein kinase CK2 in angiogenesis and retinal neovascularization. Invest Ophthalmol Vis Sci. 2004; 45:4583-4591. [PubMed: 15557471]

Lomonte P, Sullivan KF, Everett RD. Degradation of nucleosome-associated centromeric histone H3like protein CENP-A induced by herpes simplex virus type 1 protein ICP0. J Biol Chem. 2001; 276:5829-5835. [PubMed: 11053442]

Loret S, Guay G, Lippé R. Comprehensive characterization of extracellular herpes simplex virus type 1 virions. J Virol. 2008; 82:8605-8618. [PubMed: 18596102]

Meggio F, Pinna LA. One-thousand-and-one substrates of protein kinase CK2? FASEB J. 2003; 17:349-368. [PubMed: 12631575]

Montenarh M. Cellular regulators of protein kinase CK2. Cell Tissue Res. 2010; 342:139-146. [PubMed: 20976471]

Morrison EE, Wang YF, Meredith DM. Phosphorylation of structural components promotes dissociation of the herpes simplex virus type 1 tegument. J Virol. 1998; 72:7108-7114. [PubMed: 9696804]

Mossman KL, Saffran HA, Smiley JR. Herpes simplex virus ICP0 mutants are hypersensitive to interferon. J Virol. 2000; 74:2052-2056. [PubMed: 10644380]

O'Reilly D, Hanscombe O, O'Hare P. A single serine residue at position 375 of VP16 is critical for complex assembly with Oct- 1 and HCF and is a target of phosphorylation by casein kinase II. EMBO J. 1997; 16:2420-2430. [PubMed: 9171355]

Pagano MA, Bain J, Kazimierczuk Z, Sarno S, Ruzzene M, Di Maira G, Elliott M, Orzeszko A, Cozza G, Meggio F, Pinna LA. The selectivity of inhibitors of protein kinase CK2: an update. Biochem J. 2008; 415:353. [PubMed: 18588507] 
Parkinson J, Lees-Miller SP, Everett RD. Herpes simplex virus type 1 immediate-early protein vmw110 induces the proteasome-dependent degradation of the catalytic subunit of DNAdependent protein kinase. J Virol. 1999; 73:650-657. [PubMed: 9847370]

Potel C, Elliott G. Phosphorylation of the herpes simplex virus tegument protein VP22 has no effect on incorporation of VP22 into the virus but is involved in optimal expression and virion packaging of ICP0. J Virol. 2005; 79:14057-14068. [PubMed: 16254340]

Rojas S, Corbin-Lickfett KA, Escudero-Paunetto L, Sandri-Goldin RM. ICP27 phosphorylation site mutants are defective in herpes simplex virus 1 replication and gene expression. J Virol. 2010; 84:2200-2211. [PubMed: 20015991]

Rowe J, Greenblatt RJ, Liu D, Moffat JF. Compounds that target host cell proteins prevent varicellazoster virus replication in culture, ex vivo, and in SCID-Hu mice. Antiviral Res. 2010; 86:276285. [PubMed: 20307580]

Sacks WR, Greene CC, Aschman DP, Schaffer PA. Herpes simplex virus type 1 ICP27 is an essential regulatory protein. J Virol. 1985; 55:796-805. [PubMed: 2991596]

Samaniego LA, Wu N, DeLuca NA. The herpes simplex virus immediate-early protein ICP0 affects transcription from the viral genome and infected-cell survival in the absence of ICP4 and ICP27. J Virol. 1997; 71:4614-4625. [PubMed: 9151855]

Sandri-Goldin RM. The many roles of the regulatory protein ICP27 during herpes simplex virus infection. Front Biosci. 2008; 13:5241-56. [PubMed: 18508584]

Scaglioni PP, Yung TM, Cai LF, Erdjument-Bromage H, Kaufman AJ, Singh B, Teruya-Feldstein J, Tempst P, Pandolfi PP. A CK2-dependent mechanism for degradation of the PML tumor suppressor. Cell. 2006; 126:269-283. [PubMed: 16873060]

Schaffer PA, Aron GM, Biswal N, Benyesh-Melnick M. Temperature-sensitive mutants of herpes simplex virus type 1: isolation, complementation and partial characterization. Virology. 1973; 52:57-71. [PubMed: 4372782]

Schang LM, Phillips J, Schaffer PA. Requirement for cellular cyclin-dependent kinases in herpes simplex virus replication and transcription. J Virol. 1998; 72:5626-5637. [PubMed: 9621021]

Smith KO. Relationship between the envelope and the infectivity of herpes simplex virus. Proc Soc Exp Biol Med. 1964; 115:814-816. [PubMed: 14155835]

Sun Z, Ren H, Liu Y, Teeling JL, Gu J. Phosphorylation of RIG-I by casein kinase II inhibits its antiviral response. J Virol. 2011; 85:1036-1047. [PubMed: 21068236]

Wang S, Fischer PM. Cyclin-dependent kinase 9: a key transcriptional regulator and potential drug target in oncology, virology and cardiology. Trends Biochem Sci. 2008; 29:302-313.

Whalen SG, Marcellus RC, Barbeau D, Branton PE. Importance of the Ser-132 phosphorylation site in cell transformation and apoptosis induced by the adenovirus type 5 E1A protein. J Virol. 1996; 70:5373-5383. [PubMed: 8764048]

Wisner T, Brunetti C, Dingwell K, Johnson DC. The extracellular domain of herpes simplex virus gE is sufficient for accumulation at cell junctions but not for cell-to-cell spread. J Virol. 2000; 74:2278-2287. [PubMed: 10666258]

Xia K, Knipe DM, DeLuca NA. Role of protein kinase A and the serine-rich region of herpes simplex virus type 1 ICP4 in viral replication. J Virol. 1996; 70:1050-1060. [PubMed: 8551563]

Zhi Y, Sandri-Goldin RM. Analysis of the phosphorylation sites of herpes simplex virus type 1 regulatory protein ICP27. J Virol. 1999; 73:3246-3257. [PubMed: 10074178] 


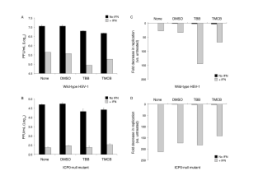

FIG. 1.

The effect of IFN- $\beta$ and CK2 inhibitors on viral replication. HEL cells were pretreated with or without IFN- $\beta$ for $16 \mathrm{~h}$ and subsequently infected with wild-type HSV-1, strain KOS, (A $\&$ C) or an ICP0 null mutant, 7134, (B \& D) at 1 PFU per cell in the presence of IFN- $\beta$, DMSO (vehicle), TBB, or TMCB or a combination of IFN and DMSO, TBB, or TMCB. At 24 hpi, infected cells were harvested, and wild-type HSV-1was titered on Vero cells and the ICP0 null mutanton L7 cells. The data shown in A and B are the mean titers ( \pm SEM) of two experiments performed in duplicate; $\mathrm{C}$ and $\mathrm{D}$ are the titers expressed as fold decrease relative to untreated cells. 


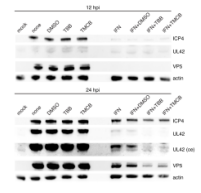

FIG. 2.

The combination of CK2 inhibitor and IFN- $\beta$ decreases early and late protein levels. HEL cells were treated and infected as described in Figure 1. At 12 and 24 hpi, cells were washed with PBS before being resuspended into loading buffer. Lysates were resolved by SDSPAGE and analyzed by western blot for ICP4, UL42, VP5, or $\beta$-actin expression. Band intensities were measured by densitometry analyses using ImageJ. UL42 (ce):the UL42 24 hpi lanes contrast enhanced (ce) using Adobe Photoshop. 


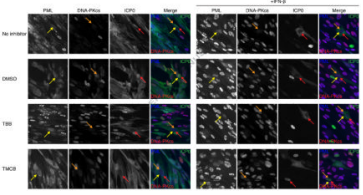

FIG 3.

CK2 inhibitors do not prevent the loss of PML and DNA-PKcs staining mediated by ICP0. HEL cells were treated and infected as described in Figure 1. At $12 \mathrm{hpi}$, cells were fixed and stained with antibodies against DNA-PKcs, PML, and ICP0. PML is shown as blue, DNA$\mathrm{PKcs}$ as red, and ICP0 as green in the merged image. The yellow, orange, and red arrows indicate a cell that stains positive for ICP0 (red arrow) but has reduced or no apparent staining for PML (yellow arrow) and DNA-PKcs (orange arrow). 


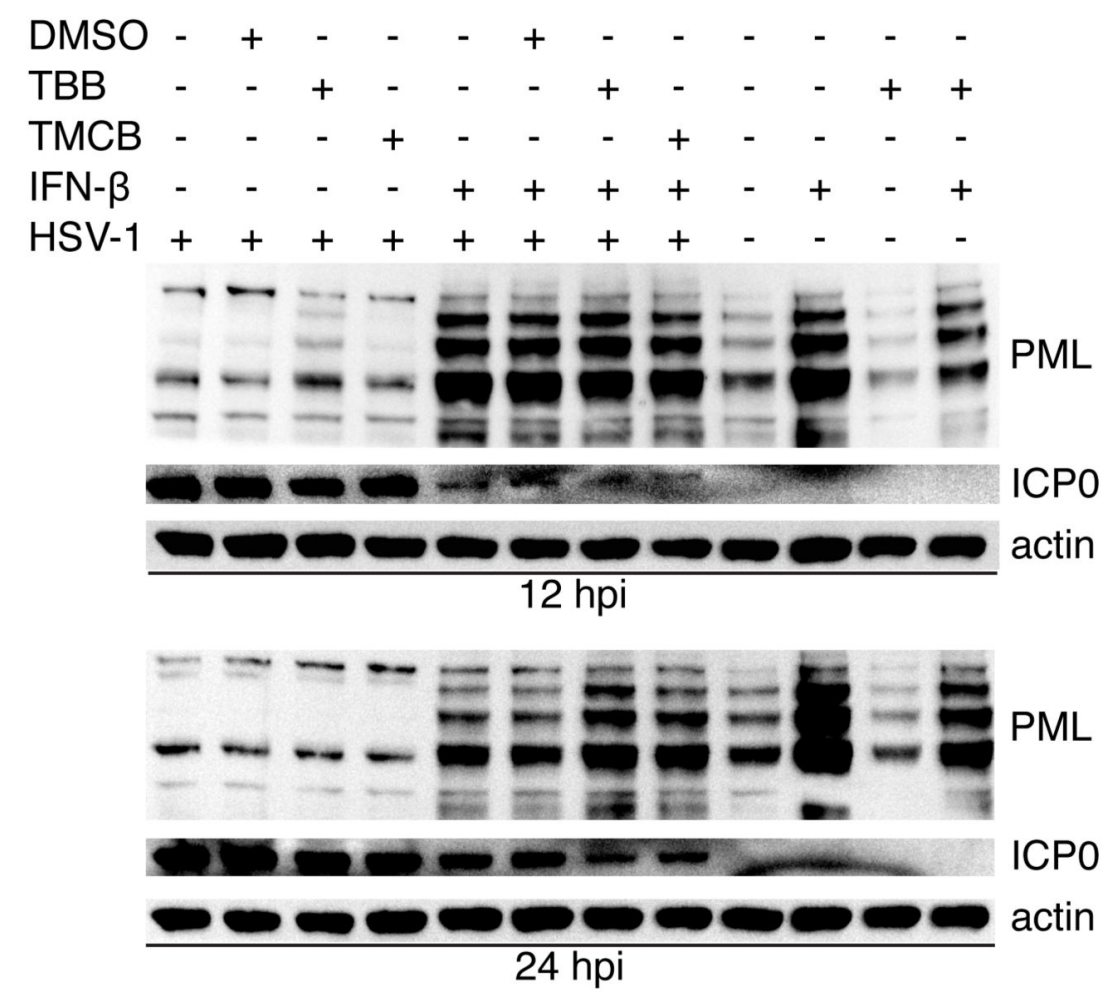

FIG 4.

CK2 inhibitors do not stabilize PML levels during infection. HEL cells were treated, as described in Figure 1, infected with wild-type HSV-1, and harvested at 12 and 24 hpi. Cell lysates were analyzed for PML, ICP0, or $\beta$-actin expression by western blot analyses. 
TABLE 1

Plaque size and plating efficiency of HSV-1 in CK2 inhibitor-, IFN- $\beta$-, or IFN- $\beta$ plus CK2 inhibitor-treated cells.

\begin{tabular}{|c|c|c|c|c|}
\hline Treatment & Area $\left(\mathbf{m m}^{2}\right)^{a}$ & Area (fold change) $b$ & Area (fold decrease vs IFN- $\beta)^{c}$ & $\begin{array}{c}\text { Plating efficiency (fold } \\
\text { decrease) }\end{array}$ \\
\hline None & $5.470( \pm 0.564)$ & - & - & - \\
\hline DMSO & $4.670( \pm 0.644)$ & $\downarrow 1.2$ & - & 1 \\
\hline TBB & $1.410( \pm 0.193)$ & $\downarrow 3.9$ & - & 1 \\
\hline TMCB & $3.830( \pm 0.414)$ & $\downarrow 1.4$ & - & $\downarrow 2$ \\
\hline $50 \mathrm{U} / \mathrm{mL}$ IFN- $\beta$ & $1.160( \pm 0.126)$ & $\downarrow 4.7$ & - & $\downarrow 4$ \\
\hline $50 \mathrm{U} / \mathrm{mL}$ IFN- $\beta$ + DMSO & $0.970( \pm 0.106)$ & $\downarrow 5.6$ & $\downarrow 1.2$ & $\downarrow 4$ \\
\hline $50 \mathrm{U} / \mathrm{mL}$ IFN- $\beta+$ TBB & $0.130( \pm 0.011)$ & $\downarrow 42.1$ & $\downarrow 8.9^{*}$ & $\downarrow 9$ \\
\hline $50 \mathrm{U} / \mathrm{mL}$ IFN- $\beta+$ TMCB & $0.530( \pm 0.065)$ & $\downarrow 10.3$ & $\downarrow 2.2^{*}$ & $\downarrow 7$ \\
\hline $1000 \mathrm{U} / \mathrm{mL}$ IFN- $\beta$ & $0.210( \pm 0.025)$ & $\downarrow 26.0$ & - & $\downarrow 25$ \\
\hline $1000 \mathrm{U} / \mathrm{mL}$ IFN- $\beta$ + DMSO & $0.120( \pm 0.011)$ & $\downarrow 45.6$ & $\downarrow 1.8^{*}$ & $\downarrow 27$ \\
\hline $1000 \mathrm{U} / \mathrm{mL}$ IFN- $\beta+$ TBB & $0.060( \pm 0.005)$ & $\downarrow 91.2$ & $\downarrow 3.5^{*}$ & $\downarrow 71$ \\
\hline $1000 \mathrm{U} / \mathrm{mL}$ IFN $-\beta+\mathrm{TMCB}$ & $0.080( \pm 0.007)$ & $\downarrow 68.4$ & $\downarrow 2.6^{*}$ & $\downarrow 52$ \\
\hline
\end{tabular}

${ }^{a}$ Plaque areas were determined by capturing images of immunohistochemically stained plates with a flatbed scanner and measuring the number of pixels that corresponded to an individual plaque in Adobe Photoshop. The pixel values were converted to $\mathrm{mm}^{2}$ by dividing that value by the number of pixels per inch for the image. Four to twenty plaques were measured per treatment for two experiments, and the results for one experiment are shown above. Data are shown as the means $( \pm$ SEM $)$.

${ }^{b}$ Fold change relative to untreated cells ("None").

${ }^{c}$ One way ANOVA $(\mathrm{P}<0.05)$, Bonferroni's multiple comparison post-test $(*, \mathrm{P}<0.05)$ compared to the IFN-treated group

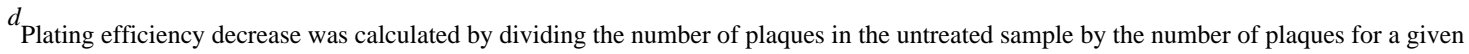
treatment. The data shown are the means of two experiments. 
TABLE 2

Plating efficiency of VSV and Ad5 in CK2 inhibitor-, IFN- $\beta-$, or IFN- $\beta$ plus CK2 inhibitor-treated cells.

\begin{tabular}{llc}
\hline Virus & Treatment & Plating efficiency (fold decrease) $^{a}$ \\
\hline VSV & None & - \\
& DMSO & 1 \\
TBB & 1 \\
TMCB & 1 \\
IFN- $\beta$ & $\downarrow 100$ \\
IFN- $\beta+$ DMSO & $\downarrow 74$ \\
IFN- $\beta+$ TBB & $\downarrow 66$ \\
IFN- $\beta+$ TMCB & $\downarrow 65$ \\
\hline Ad5 & - \\
None & 1 \\
DMSO & 1 \\
TBB & 1 \\
TMCB & $\downarrow 2$ \\
IFN- $\beta$ & $\downarrow 3$ \\
IFN- $\beta+$ DMSO & $\downarrow 5$ \\
IFN- $\beta+$ TBB & $\downarrow 4$ \\
IFN- $\beta+$ TMCB & \\
&
\end{tabular}

